Article abstract-We studied 65 Huntington's disease patients and 225 at-risk individuals over the past 4 years. The rate of decline of these untreated patients from Venezuela was similar to that seen in US patients who had received neuroleptic drugs. Chorea, oculomotor dysfunction, and dysdiadochokinesis were early symptoms; parkinsonian features and dystonia came later. Juvenile patients declined nearly twice as fast as adult-onset patients. No distinctive neurologic phenotypes were seen in children of two affected parents.

NEUROLOGY 1986;36:244-249

\title{
Huntington's disease in Venezuela: Neurologic features and functional decline
}

\author{
Anne B. Young, MD, PhD; Ira Shoulson, MD; John B. Penney, MD; Simon Starosta-Rubinstein, MD; \\ Fidela Gomez, RN; Helen Travers, MS; Maria A. Ramos-Arroyo, MD; S. Robert Snodgrass, MD; \\ Ernesto Bonilla, MD, PhD; Humberto Moreno, MD; and Nancy S. Wexler, PhD
}

Knowledge of the natural history of Huntington's disease (HD) is sparse and has been pieced together from crosssectional analysis, small populations of unrelated families, and patients who have commonly received neuroleptic drugs. ${ }^{1}$ Clarification of the natural history of HD would aid in understanding the expression of the HD gene $e^{2.3}$ that causes neuronal degeneration and clinical disability, and also in evaluating experimental therapies.

No biologic marker has been reliably linked to the degree of clinical impairment in HD. However, clinical ratings of functional capacity 4.5 show a strong linear relationship to the degree of caudate atrophy as assessed by $C^{6.7}$ and to caudate hypometabolism as measured by positron emission tomography ${ }^{8}$ Clinical features can therefore be used to rate decline and to approximate the rate of neuronal degeneration.

The HD population of Venezuela is unique for several reasons: (1) clinical features can be studied prospectively in a nonmobile, ascertained cohort; (2) there is a large affected kinship, with a single allelic determinant, ${ }^{2,3}$ minimizing the impact of genetic heterogeneity and providing a measure of clinical heterogeneity; (3) the disorder is seen in a nonmedicated population, not influenced by neuroleptic-induced motor or behavioral changes; and (4) there are uniform environmental influences including climate, nutrition, social milieu, and health care.

As a part of a genetic linkage study, ${ }^{2}$ we have made a systematic and prospective clinical evaluation of the $\mathrm{Ve}$ nezuelan HD community whose members live in clusters along the western shores of Lake Maracaibo (figure 1). We believe that a single gene-carrying progenitor gave rise to this family, which includes many marriages between affected and possible carriers of the HD gene. The HD population in Venezuela was originally described by Drs. Americo Negrette ${ }^{9}$ and Ramon Avila-Giron. ${ }^{10}$

Methods. The HD pedigree in Venezuela includes approximately 4,000 individuals from eight generations. ${ }^{2,3}$ Two hundred ninety individuals have been examined in detail neurologically, ${ }^{2}$ including 225 individuals immediately at risk and 65 with clear clinical features of the disease.

HD patients were evaluated by four neurologists (A.B.Y., I.S., J.B.P., S.S.R.) and one psychologist (N.W.). Evaluations included standardized ratings of chorea, dystonia, parkinsonism, oculomotor dysfunction, dysdiadochokinesia, dysarthria, and hyperreflexia. ${ }^{11,12}$ Scores ranged from 0 (completely normal) to 3 to 5 (very abnormal)(table 1). Functional capacity was rated by a standardized system., ${ }^{4,5}, 12$ Estimated age at onset of motor features and cognitive/behavioral profiles will be the subject of a separate report.

Clinical evaluations were conducted annually each March between 1981 and 1984. Forty-seven patients were evaluated on at least two occasions a year apart.

Results. Between 1981 and 1984, 486 neurologic examinations were performed on 290 individuals, including 65 with motor evidence of $\mathrm{HD}, 207$ with at least $50 \%$ risk for $\mathrm{HD}$, and 18 with $25 \%$ risk (table 2). Diagnosis was based on unequivocal extrapyramidal motor signs of chorea, dystonia, or parkinsonism. ${ }^{4}$ Sixty-five people (33 men, 32 women; $40.7 \pm 1.7 \mathrm{yrs}$, mean \pm SEM) had

From the University of Michigan (Drs. Young, Penney, and Starosta-Rubinstein), Ann Arbor, MI; the University of Rochester (Dr. Shoulson), Rochester, NY; the Hereditary Disease Foundation (Ms. Gomez and Dr. Wexler), Santa Monica, CA; the Mailman Research Center (Ms. Travers), Miami, FL; Indiana University (Dr. Ramos), Indianapolis, IN; the University of Southern California (Dr. Snodgrass), Los Angeles. CA; and the University of Zulia (Drs. Bonilla and Moreno), Maracaibo. Venezuela.

This investigation resulted from a contract (N01-NS-0-0452) between the National lnstitutes of Health, NINCDS (N. Wexler, principal investigator) and the University of Zulia, Maracaibo, Venezuela (E. Bonilla, principal investigator). Primary funding for this study was provided by the National Institutes of Health (USPHS grant NS22031, N. Wexler, Project Officer), the Hereditary Disease Foundation (Santa Monica, CA), the W.M. Keck Foundation (Los Angeles, CA), the Vollmer Foundation (New York, NY), and the Regenstein Foundation (Chicago, IL). Additional support for this study was provided by USPHS grants NS 00420, NS 00464, and NS 15655 for A.B.Y. and J.B.P., and NS 17978, NS 00397, and RR 00044 for I.S., and by the Lena Marcus Trust.

Presented in part at the thirty-fifth annual meeting of the American Academy of Neurology, San Diego, CA, April 1983.

Accepted for publication June 19, 1985.

Address correspondence and reprint requests to Dr. Young, University of Michigan, Neuroscience Laboratory Bldg., 1103 East Huron, Ann Arbor, MI 48104. 


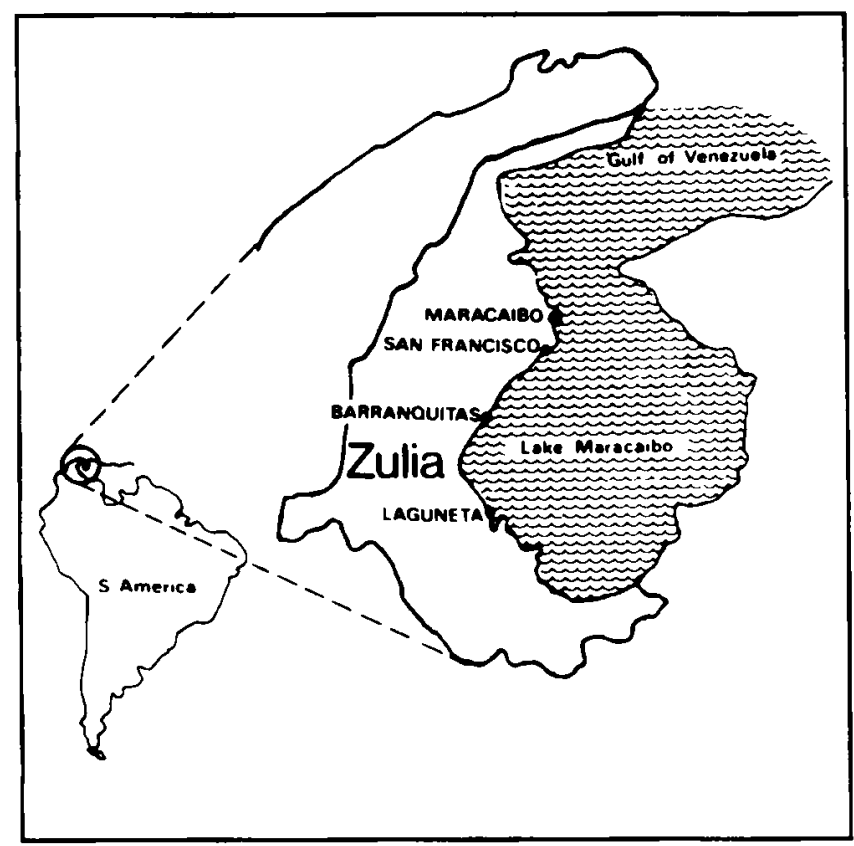

Figure 1. Map of Venezuela. The enlargement shows the Lake Maracaibo region and the three towns, San Francisco, Barranquitas, and Laguneta where subjects were examined (reproduced from reference 13).

clear features of HD; 4 had motor symptoms before age 20. Eighteen examined individuals were potentially homozygous because both mother and father were af fected. Assuming viability of all offspring, the genetic prediction in matings of parents who are both heterozygous is that $50 \%$ of offspring will be heterozygous, and $25 \%$ will be homozygous.

Of the 207 individuals with at least $50 \%$ risk, 73 showed minor motor abnormalities on examination. These "soft signs" included abnormal saccadic eye movements and optokinetic nystagmus, hyperreflexia, impaired finger tapping or rapid alternating hand movements (dysdiadochokinesia), or excessive and inappropriate movements of the fingers, hands, or toes during emotional stress without clearcut extrapyramidal signs (table 2). Presence of any of these abnormalities were recorded as soft signs and were seen in approximately one-third of the 207 at-risk individuals examined. None of those with soft signs developed overt clinical features of HD in the 3 years of study.

One hundred seventy examinations were carried out on 65 HD patients over the 3-year prospective study. One hundred five were follow-up examinations. We examined patients in all stages of illness: most were in stages II and III corresponding to total functional capacity (TFC) units 7 to 10 and 3 to 6 (figure 2).,5.12 Fewer HD patients were seen in stages IV and V, possibly because many died of other causes and because there are no long-term facilities to care for severely disabled persons. Forty-seven of the $65 \mathrm{HD}$ patients were examined at least twice at intervals from 1 to 3 years (figure 3 ). Prospective data were available for more patients in the early stages I to III of illness (TFC $=3$ to 13 ) than for the more advanced patients in stages IV and V (TFC $=$ 0 to 2 ).
Of the 47 patients who were evaluated prospectively, the average TFC score was $8.2 \pm 0.50$ units (mean \pm SEM) at the initial examination and $5.9 \pm 0.51$ units at the last examination. Average duration of follow-up was 2.2 years per patient, giving an average TFC decline of 2.3 units $/ 2.2$ yrs $=1.05 \mathrm{TFC}$ units/yr. Excluding the four juvenile cases, the average decline for adult-onset cases was 0.99 TFC units/yr. For juvenile patients, the average decline was 1.79 TFC units/yr. When average rate of TFC decline was analyzed according to stage of illness (figure 4), patients in the early stages (I to II) lost function more rapidly than those in the later stages (III to IV). Average rate of decline was 1.6 units/yr for patients initially examined in stage I, 0.9 units/yr for those in stage II, 0.5 units/yr for those in stage III, and 0.3 units/yr for those in stage IV. There was no difference in the rate of TFC decline in men and women or in patients who inherited the gene from a father or a mother.

Abnormalities of rapid alternating movements and saccades, and clearly detectable chorea were observed in the early stages (figure 5). The intensity of these signs increased in nearly linear fashion as functional capacity declined. Intensity of bradykinesia/rigidity and dystonia was minimal in the early stages, but then increased rapidly and nearly linearly.

Most patients had dysarthria and reflex abnormalities (table 3). Although speech was difficult to assess due to local dialects, dysarthria was present in $89 \%$ of patients. As with other motor signs, dysarthria was mild in the early stages of disease and increased as the disease progressed (table 3). Only one patient was anarthric. Concomitant with the dysarthria was dysphagia, which was a common symptom late in the disease.

Ninety percent of patients had hyperactive reflexes, and $30 \%$ had clonus as well. Only $10 \%$ of cases had abnormal plantar responses, either a Babinski or a dystonic posturing of toe and foot. Abnormal plantar responses were present in two of the four juvenile persons and in three advanced HD cases. Muscle weakness was not a sign in any patient.

Four juvenile-onset HD patients were evaluated. One boy had symptoms at age 3 , and two girls and one boy had symptoms at about age 11. All three had an affected father; one girl had two affected parents. The most prominent motor features in the juvenile-onset cases were bradykinesia/rigidity and dystonia. As illness progressed, dystonic features and tremor became more apparent. Three of the four juvenile patients had tremor, with both kinetic and resting components; tremor generally worsened while maintaining a posture or with action. Mild cerebellar signs were seen in one of the juvenile patients, and another patient had generalized seizures in the advanced stage of illness. All juvenile patients had prominent eye-movement abnormalities, similar to those of adult-onset cases. The rate of functional decline in the four juvenile patients (1.79 TFC units/yr) was nearly twice as rapid as the 43 patients with adult-onset ( 0.99 units/yr).

Eighteen individuals had two affected parents (table 4). These potential homozygotes included 7 men and 11 women with an average age of $27 \pm 3$ years (mean \pm 


\begin{tabular}{|c|c|c|}
\hline Chorea & $\begin{array}{l}\text { Patients were rated at rest and under stress; for } \\
\text { this analysis, the maximum overall score for the } \\
\text { patient under stress was used. }\end{array}$ & $\begin{array}{l}0 \text { No chorea } \\
1 \text { Slight and present infrequently } \\
2 \text { Moderate in amplitude but intermittent } \\
3 \text { Moderate and frequent, or continuous } \\
4 \text { Marked amplitude and continuous }\end{array}$ \\
\hline $\begin{array}{l}\text { Saccadic } \\
\text { eye movements }\end{array}$ & $\begin{array}{l}\text { Latency, accuracy, velocity, and presence of blink } \\
\text { and head movement were rated; the patient was } \\
\text { scored for overall degree of impairment on all five } \\
\text { tests. }\end{array}$ & $\begin{array}{ll}0 & \text { No impairment } \\
1 & \text { Mild impairment } \\
2 & \text { Moderate impairment } \\
3 & \text { Marked impairment }\end{array}$ \\
\hline Dysdiadochokinesis & $\begin{array}{l}\text { Tapping index finger against thumb and } \\
\text { alternately pronating and supinating the hand } \\
\text { were rated, and the average score was taken. }\end{array}$ & $\begin{array}{l}0 \geq 3-4 / \mathrm{sec} \text { and smooth } \\
13-4 / \mathrm{sec} \text { but arrhythmic } \\
2 \leq 2 / \mathrm{sec} \\
3 \text { Cannot perform }\end{array}$ \\
\hline $\begin{array}{l}\text { Bradykinesia/ } \\
\text { rigidity }\end{array}$ & $\begin{array}{l}\text { Overall speed of movement and resistance to } \\
\text { passive movement were scored and averaged. }\end{array}$ & $\begin{array}{ll}0 & \text { Absent } \\
1 & \text { Mild } \\
2 & \text { Moderate } \\
3 & \text { Severe }\end{array}$ \\
\hline Dystonia & $\begin{array}{l}\text { Axial and limb dystonic posturing was scored; the } \\
\text { overall score was used. }\end{array}$ & $\begin{array}{l}0 \text { Absent } \\
1 \text { Slight and intermittent } \\
2 \text { Moderate and frequent } \\
3 \text { Marked and continuous }\end{array}$ \\
\hline Speech & $\begin{array}{l}\text { Evaluated rate, rhythm, and clarity of speech, and } \\
\text { ability of patient to say ta, pa, and ka; the overall } \\
\text { score was used. }\end{array}$ & $\begin{array}{l}0 \text { Normal } \\
1 \text { Slightly abnormal } \\
2 \text { Impaired but intelligible } \\
3 \text { Moderately abnormal, patient must repeat } \\
\text { phrases often } \\
4 \text { Occasional intelligible word } \\
5 \text { Anarthric }\end{array}$ \\
\hline Reflexes & $\begin{array}{l}\text { Composite score of upper and lower extremity } \\
\text { reflexes was used. }\end{array}$ & $\begin{array}{ll}0 & \text { Normal } \\
1 & \text { Hypoactive } \\
2 & \text { Hyperactive } \\
3 & \text { Hyperactive with clonus }\end{array}$ \\
\hline Plantar responses & Stimulate sole of each foot separately. & $\begin{array}{l}0 \text { Normal } \\
1 \text { Abnormal }\end{array}$ \\
\hline
\end{tabular}

- Other clinical ratings were also recorded but not analyzed specifically: optokinetic responses, fixation, smooth pursuit, range of eye movements. motor impersistence, strength, finger-to-nose, posture, postural recovery, and gait.

SEM). Five had definite HD. Three had adult-onset HD; two had juvenile-onset. Eight of the 18 potentially homozygous individuals had soft signs. None of those potentially homozygous had any unusual motor features that might indicate a distinctive phenotypic expression.

Discussion. All motor forms of HD were seen in this Venezuelan kindred. Ninety-four percent of patients were adult-onset, and $6 \%$ were juvenile-onset. Within the adult-onset patients, there was variation in motor features as in other studies. ${ }^{4,13}$

Adult-onset HD was a progressive illness with an overall average rate of decline of about 1 TFC unit/yr. The rate of decline varied among patients, but those in the earliest stages of illness generally declined faster than more advanced patients. This pattern is probably inherent in the TFC rating scale, which was designed to be more sensitive to change in the earliest stages of
Table 2. Summary of neurologic exams performed between 1981 and 1984

Total number of neurologic examinations 486

Number of persons examined

Number of at-risk individuals: $50 \%$ at-risk $25 \%$ at-risk

290 207*

Number of at-risk individuals with "soft signs"

Number of $\mathrm{HD}$ patients:

men women

Number of juvenile-onset cases (onset $<20 \mathrm{yr}$ )

Number of potential homozygotes

- Eighteen individuals (table 4) had greater than $50 \%$ risk.

+ "Soft signs" were defined as abnormal saccades and optokinetic nystagmus and/or hyperreflexia and/or impaired fine motor coordination by finger tapping and rapidly alternating hand movements, and/or varying adventitious movements in individuals who were not clearly choreic. 
HD. ${ }^{5,12}$ The more rapid decline in early stages implies that patients are incapacitated in occupational and personal roles early in the 10- to 20-year decline of HD patients in both the urban United States ${ }^{4,12}$ and rural Venezuela. The overall rate of decline in this Venezuelan family was slightly less rapid but similar to that of the more heterogeneous and medicated US HD patients. ${ }^{4.12}$ Therefore, the neuroleptic agents used to treat $\mathrm{HD}$ are at best palliative and do not alter the course of HD. ${ }^{5}$ This observation further reinforces the therapeutic admonition that neuroleptic agents be used sparingly in $\mathrm{HD}$ for the treatment of hyperkinetic and psychiatric symptoms. ${ }^{1,14}$

The motor features and functional decline in the adults were also similar to those seen in other studies..$^{4.12}$ Chorea, oculomotor dysfunction, and disturbances in rapid alternating movements were early signs, showed linear increase in intensity with time, and then reached a plateau in advanced stages. Parkinsonian features and dystonia were minimal in early stages, surfaced in midstages, and continued to intensify in advanced illness. Dysarthria and hyperactive reflexes were common, but anarthria and extensor plantar responses were rare. Perhaps this reflects the short period of time patients survive in stage $V$ of the disease. Since decline in TFC parallels the radiographic extent of caudate atrophy ${ }^{6.8}$ and glucose hypometabolism, ${ }^{8}$ there may be neuropathologic parallels for these differing patterns of

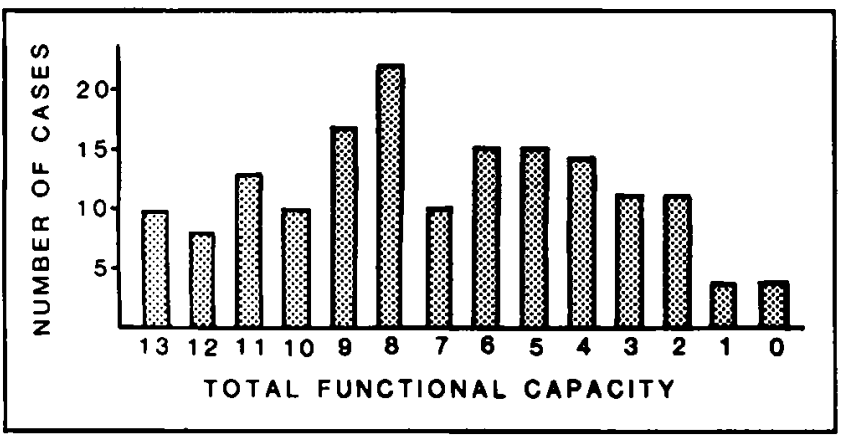

Figure 2. Frequency distribution of patient examinations (total $N=170$ ) between 1981 and 1984 according to their total functional capacity scores. Some patients were examined more than once, and all exams completed at least 1 year apart are included. motor decline. Selective sites of neuronal degeneration, cumulative loss of vulnerable neurons at one or more sites, or a combination of these factors may explain the separate decline of the different motor features. ${ }^{14} \mathrm{How}$ ever, our data indicate that the parkinsonism and dystonia are not drug effects but are rather due to neuronal degeneration.

The four young patients demonstrated all of the characteristics of juvenile HD..$^{13.15,16}$ Dystonia and parkinsonism predominated, and there was little chorea. Cerebellar signs, tremor, and seizures were seen later. As noted by others, ${ }^{13.15 .16}$ the decline of juvenile patients seemed more rapid than in adults, perhaps because of accelerated or more widespread neuronal degeneration. ${ }^{15,16}$ Maternal or paternal transmission of the gene may influence the rate of clinical decline or age at onset, ${ }^{17,18}$ but we found no differences between maternal or paternal transmission and rate of TFC decline. However, we could not address this issue with clarity because of the high frequency of marriages between two at-risk

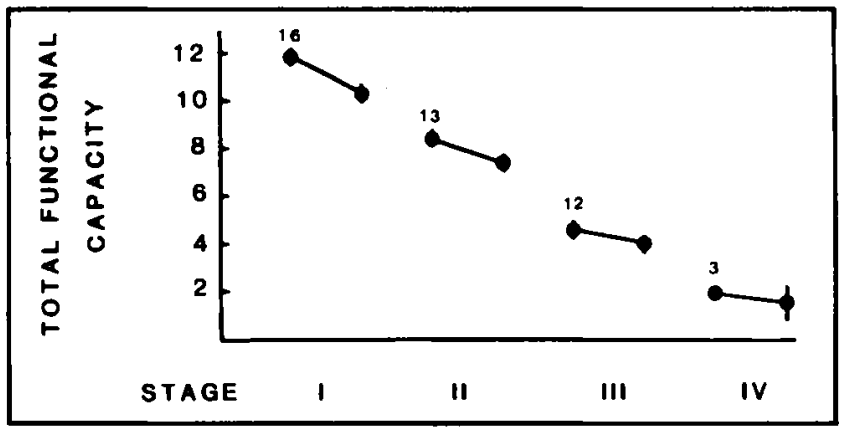

Figure 4. Average rate of decline according to stages I to IV of illness $(N=47)$. The mean total functional capacity $(T F C)$ values (bars $=S E M)$ for patients initially examined in stages $I(T F C=11$ to 13$), I I(T F C=7$ to 10$), I I I(T F C=$ 3 to 6$)$, and $I V(T F C=1$ to 2$)$ are plotted as the first point for each stage. The second point for each stage is derived by calculating the average decline in TFC (units/yr) for each patient per stage, and then subtracting this value from the initial TFC. Numbers above each curve denote $N$ in this stage at the time of initial examination. Average rate of decline (TFC units $/ y$ ) for each stage was: stage $I, 1.6 \pm 0.2$ stage II, $0.9 \pm 0.5$; stage III, $0.5 \pm 0.4$; and stage IV, $0.3 \pm$ 0.9 .

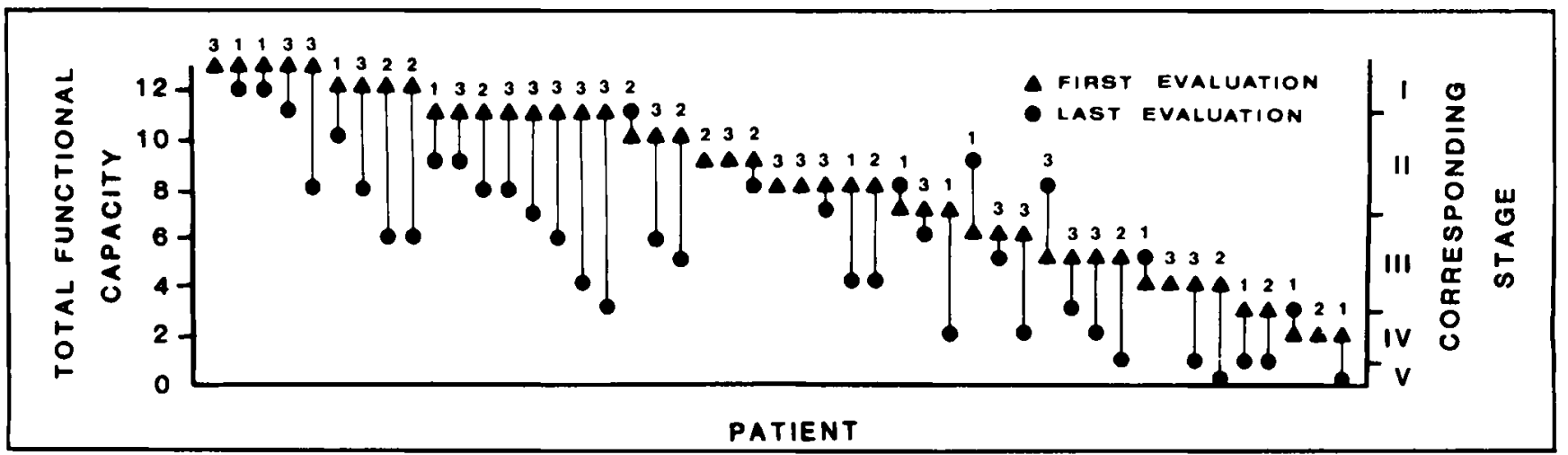

Figure 3. Total functional capacity data (TFC scoring units) for 47 patients who were examined on at least two occasions, at least 1 year apart. The scores at the initial (triangles) and last (circles) examinations are illustrated. The duration of followup (years) for each patient is reported as a number above each case. 


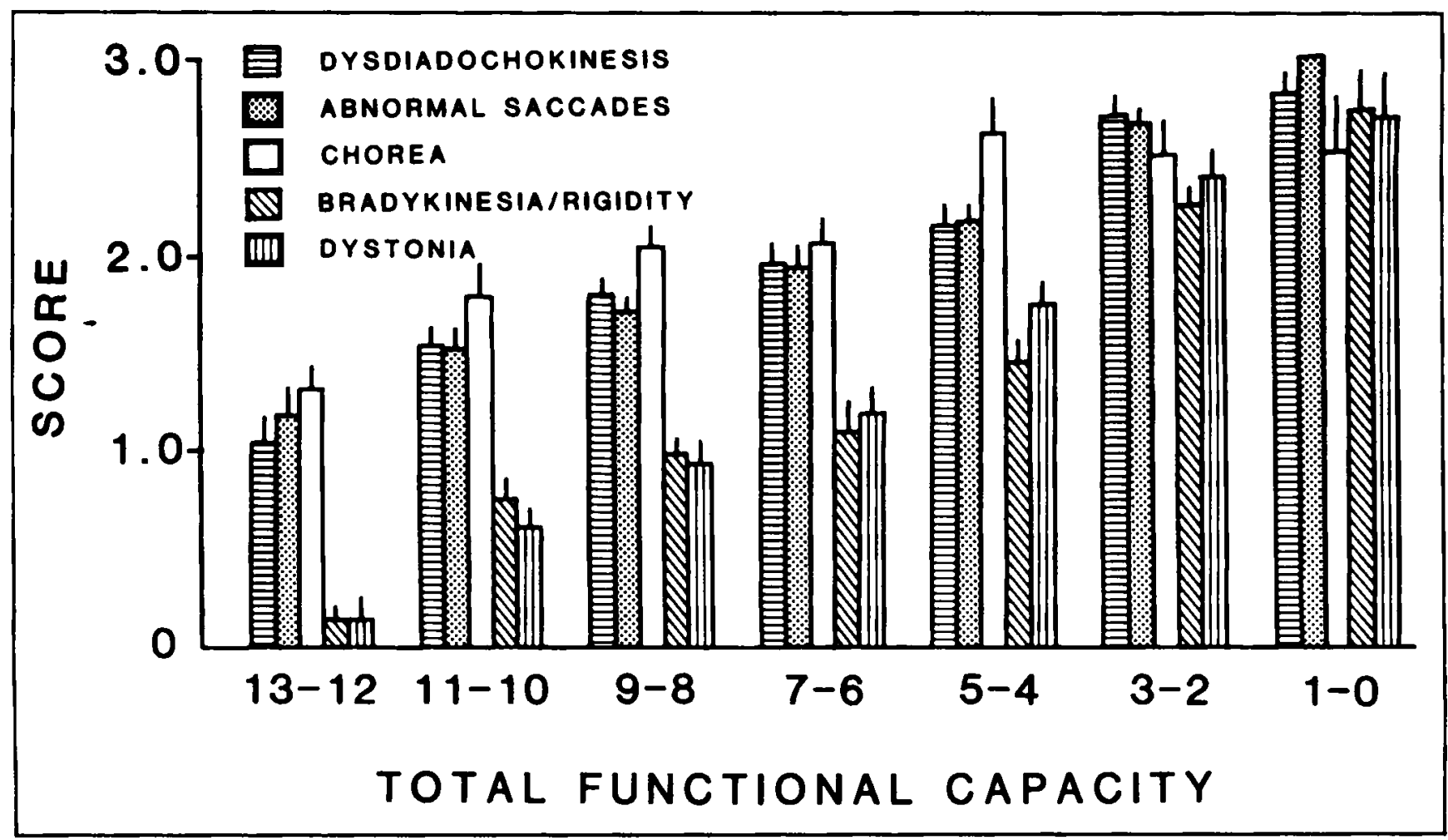

Figure 5. Profile of motor features according to total functional capacity (TFC). The scores (mean $\pm S E M$, bars) for dysdiadochokinesis, abnormal saccades, chorea, bradykinesia/rigidity, and dystonia were averaged for patients $(N=43)$ and plotted according to TFC grouping 13-12,11-10, 9-8,7-6, 5-4, 3-2 and 1-0. Criteria for scoring and rating are summarized in table 1. Juvenile cases were not included in this analysis.

Table 3. Dysarthria and reflex changes in Venezuelan HD population

\begin{tabular}{|c|c|c|}
\hline Symptom & Score* & $\begin{array}{l}\text { \% of patients } \\
\text { with symptom }\end{array}$ \\
\hline \multicolumn{3}{|l|}{ Dysarthria } \\
\hline Stage I & $0.9 \pm 0.2$ & $60 \%$ \\
\hline II & $1.8 \pm 0.1$ & $92 \%$ \\
\hline III & $2.4 \pm 0.1$ & $100 \%$ \\
\hline IV & $3.4 \pm 0.2$ & $100 \%$ \\
\hline V & $4.1 \pm 0.3$ & $100 \%$ \\
\hline \multirow[t]{4}{*}{ Reflexes } & 0 & $12 \%$ \\
\hline & 1 & $0 \%$ \\
\hline & 2 & $59 \%$ \\
\hline & 3 & $29 \%$ \\
\hline \multirow[t]{2}{*}{ Plantar response } & 0 & $92 \%$ \\
\hline & 1 & $8 \%$ \\
\hline \multicolumn{3}{|c|}{$\begin{array}{l}\text { - Scores are those defined in table } 1 \text {. For dysarthria, scores from each } \\
\text { stage are given as mean } \pm \text { SEM. }\end{array}$} \\
\hline
\end{tabular}

individuals and between at-risk and affected persons. More patients will be needed to clarify the influence of parental transmission on the rate of functional decline.

Among the many at-risk individuals, about one-third had soft signs on examination that were insufficient to confirm the diagnosis. None of them have developed clear motor abnormalities, but the soft signs may yet be important as we follow the kindred. There may be a long period before the onset of overt signs. . $^{8.19 .20}$

Statistically, one quarter of children of two affected parents should be homozygous if the homozygous state
Table 4. Characteristics of potential homozygotes who have been examined*

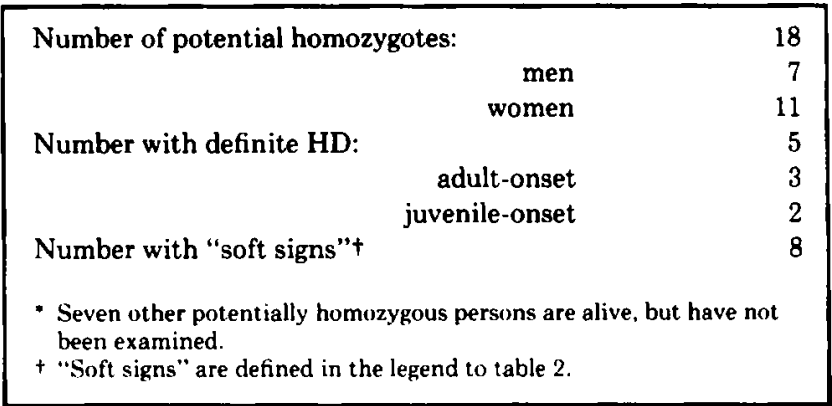

is viable. No unusual occurrence of miscarriages was reported among the mothers of these individuals. Furthermore, there was no distinctive neurologic phenotype of affected individuals in this group. In fact, there was no apparent difference between affected potentially homozygous and heterozygous patients. If there is no difference, HD would be an unusual illness because the dominant disorder would be expressed without obvious gene-dose effect.

\section{Acknowledgments}

We thank our many coworkers in Venezuela (A. Negrette, R. AvilaGiron, I. DeQuiroz, J. Esteves, M. Villalobos, D. Colmenares, and N. Marsol) and in the United States (P.M. Conneally, J.F. Gusella, D. Housman, B. Jones, L. Dougherty, M. and W. Dorn, S. Bailey, J.B. Martin, and A.R. Wexler). Mrs. Ruth Nobel assisted in preparation of the manuscript. 


\section{References}

1. Shoulson I. Huntington's disease: a decade of progress. Neurol Clin 1984;2:515-26.

2. Gusella JF, Wexler NS, Conneally PM, et al. A polymorphic DNA marker genetically linked to Huntington's disease. Nature 1983;306:234-8.

3. Gusella JF, Tanzi RE, Anderson MA, et al. DNA markers for nervous system diseases. Science 1984;225:1320-6.

4. Shoulson I. Care of patients and families with Huntington's disease. In: Marsden CD, Fahn S, eds. Movement disorders (International Medical Review Series). London: Butterworth Scientific, 1982:277-90.

5. Shoulson I. Huntington's disease: functional capacities in patients treated with neuroleptic and antidepressant drugs. Neurology (NY) 1981;31:1333-5.

6. Shoulson I, Plassche W, Odoroff C. Huntington's disease: caudate atrophy paraljels functional impairment. Neurology (NY) 1982;32:A143.

7. Stober T, Mussow W, Schimrigk K. Bicaudate diameter: the most specific and simple CT parameter in the diagnosis of Huntington's disease. Neuroradiology 1984;26:25-8.

8. Penney JB, Young AB, Berent $S$, et al. Positron emission tomographic (PET) scanning in Huntington's disease: studies of 18F-2-fluoro-2-deoxy-D-glucose [' $\left.{ }^{x} F D G\right]$ uptake in 12 drug-free cases. Soc for Neuroscience Abstracts 1984;10:994.

9. Negrette A. Corea de Huntington (Estudio de una sola familia investigada, traves de varias generaciones). Talleres Graficos, Univ. Zulia, Maracaibo, Venezuela 1963.
10. Avila-Giron R. Medical and social aspects of Huntington's chorea in the state of Zulia, Venezuela. Adv Neurol 1973;1:261-6.

11. Shoulson I, Goldblatt D, Chariton M, Joynt RJ. Huntington's disease: treatment with muscimol, a GABA-mimetic drug. Ann Neurol 1978;4:279-84.

12. Shoulson I. Huntington's disease: anti-neurotoxic therapeutic strategies. In: Fuxe K, Roberts P, Schwarcz R, eds. Excitotoxins. London: MacMillan, 1983:343-53.

13. Hayden M. Huntington's chorea. Berlin: Springer-Verlag, 1981:1-192.

14. Shoulson I. Huntington's disease. In: Asbury AK, McKhann GM, McDonald WI, eds. Diseases of the nervous system. Philadelphia: WB Saunders, Ardmore Medical Books (in press).

15. Goebel HH, Heipertz R, Scholz W, Iqbal K, Tellez-Nagel I. Juvenile Huntington chorea: clinical, ultrastructural, and biochemical studies. Neurology (NY) 1978;28:23-31.

16. Osborne JP, Munson P, Burman D. Huntington's chorea: report of 3 cases and review of the literature. Arch Dis Child 1982;57:99-103.

17. Myers RH, Goldman D, Bird ED, et al. Maternal transmission in Huntington's disease. Lancet 1983;1:208-10.

18. Went LN, Vegter-Van der Vlis M, Bruyn GW. Parental transmisgion in Huntington's disease. Lancet 1984;1:1100-2.

19. Kuhl DE, Metter EJ, Riege WH, Markham CH. Patterns of cerebral glucose utilization in Parkinson's disease and Huntington's disease. Ann Neurol 1984;15:S119-25.

20. Mazziota JC, Wapenski J, Phelps M. Cerebral metabolic responses to complex motor tasks: normal subjects versus patients with Huntington's disease. Soc for Neurosci Abstracts 1984;10:523. 


\section{Neurology}

Huntington's disease in Venezuela: Neurologic features and functional decline Anne B. Young, Ira Shoulson, John B. Penney, et al.

Neurology 1986;36;244

DOI 10.1212/WNL.36.2.244

\section{This information is current as of February 1, 1986}

\section{Updated Information \&}

Services

Citations

Permissions \& Licensing

Reprints including high resolution figures, can be found at: http://n.neurology.org/content/36/2/244.full

This article has been cited by 2 HighWire-hosted articles: http://n.neurology.org/content/36/2/244.full\#\#otherarticles

Information about reproducing this article in parts (figures,tables) or in its entirety can be found online at: http://www.neurology.org/about/about_the_journal\#permission $\mathrm{s}$

Information about ordering reprints can be found online: http://n.neurology.org/subscribers/advertise

Neurology ${ }^{\circledR}$ is the official journal of the American Academy of Neurology. Published continuously since 1951, it is now a weekly with 48 issues per year. Copyright $(\subset) 1986$ by the American Academy of Neurology. All rights reserved. Print ISSN: 0028-3878. Online ISSN: 1526-632X.

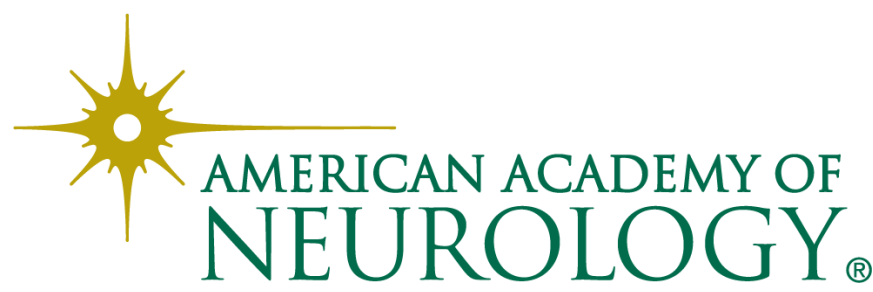

